\title{
Optimizing the Economic Information Transparency Level of High-Tech Enterprises in the Post-Industrial Globalized Economy
}

\begin{abstract}
O.N. Dmitriev ${ }^{1}$, S.V. Novikov ${ }^{2}$
Abstract:

Purpose: Managerial conditions of economic operation of a high technology enterprise as it integrates into the global economy that is essentially postindustrial and globalized were considered in this article.

Design/Methodology/Approach: An inevitable immersion of the enterprise into the well-developed external infosphere, as well as a membrane borderline between the external and the internal infospheres were shown. The enterprise was represented dually - as both a donor and a recipient of information resources.

Findings: An interpretation of the content of the infosphere was presented. Multiple causes of the discrete nature of the enterprise's infosphere implementation were shown. The concept of "informational economic transparency" of an enterprise was introduced, and multiple components determining transparency levels were described.

Practical Implications: The influence of transformations of informational economic transparency of an enterprise on external impacts on it from legal relations parties. Positive and negative effect of increases and decreases in the informational economic transparency of the enterprise were highlighted in the context of its influence on the economic counterpart and conflict-studies situations. The understanding of the specialized control object was provided. The optimizability of a level of the transparency in the aspect of target orientation of the enterprise was demonstrated.

Originality/Value: A structural prototype to the primary support managerial toolkit in the shape of a DSS, a recommender system, allowing to conduct required feasibility studies of managerial decisions was proposed.
\end{abstract}

Keywords: High technology enterprise, globalization, economic informational transparency, DSS, decision optimization.

JEL Classification: B41, C18, C53, C63, D01.

Paper type: Research article.

\footnotetext{
${ }^{1}$ PhD (Engineering), Full Doctor (Economics), Professor of Management, Professor at High-Technology Industry Production Management and Marketing Department, Moscow Aviation Institute (National Research University), E-mail: olegdmitriev@yandex.ru

${ }^{2}$ PhD (Economics), Associate Professor and Acting Director in Scientific Research of the Institute of Engineering and Economics, Moscow Aviation Institute (National Research University),E-mail: ncsrm@mail.ru
} 


\section{Introduction}

It is a generally accepted fact that globalization and top priority given to information and information resources as manufactured and consumed commodity product are the characteristic features of modern economy. It is characteristic of the business activity conducted by enterprises (especially those categorized as high-tech enterprises) that their managerial area considerably predominates over the manufacturing area proper in terms of its influence on the enterprise's performance and good standing. In many cases, managerial technologies have become critically more important than manufacturing technologies.

Amid the integration-type globalization of the world economy both in the contexts of regional consolidations like the European Community and in terms of integration of markets - including that under the World Trade Organization regime - there inevitably emerges an integrated and global information sphere, the infosphere, where various legal relations parties operate, including high technology enterprises. In the course of their operation, they can be either donors or recipients of economic information, with the generation and perception of that information being of both an active and a passive nature, where the external and the internal infospheres are separated by an imaginary membrane that is controlled from within and from the outside and acts as a twoway filter.

Its two-way permeability - primarily, from the internal infosphere to the external one - is variable, transformable, and selective in terms of its components, and significantly influences the good standing and the performance of the enterprise, which is far from being perceived as a managerial issue by both researchers and experts. Moreover, respective manipulations are not supported by advanced recommender systems, DSSs. This is why we see any research into transparent management of a high technology enterprise, including that of the enterprise's financial and economic enterprise, as beneficial to the managerial staff on the microlevel, mesolevel, and macrolevel.

\section{Research background and its sufficiency}

It was decades ago when the problem of the research into and the formation of infospheres of the operation of high technology enterprises was first pinpointed and studied. Moreover, multiple attempts to solve it for purely practical applications were made. A lot of effort was put into research by both scientists and experts in a number of areas in many countries. Naturally, we gave high priority to research conducted by Russian scientists when we assessed our predecessors' work. Among the areas researched into previously, the following are of interest: 
- The area of fundamental research of interpreting information as a special kind of objects described through constructs of theoretical abstractions. Research into general entropy information theory that has become classic are worth mentioning first and foremost (Shannon, 2002; Wiener, 1968);

- The area of formation, aggregation, ordering, and maintenance of the infosphere in the context of provision of managerial activities of the staff of self-governed enterprises, as well as industries' governing agencies, with information support of management was formed to support and to maintain by providing primary and intermediary data to enterprises' managerial staff so that they could exercise their managerial activities. The area in question was related, among other things, to the development of information reference management systems in the USSR (Glushkov, 1974), the design of database management systems (Shpak, 2007) in the past, and now pertains to dedicated web portals and various networks - from local to global (Leokhin, 2009). As far as the Soviet aviation industry is concerned, the pivotal role of Yu.V. Sukhotin, Yu.M. Cherkasov, V.F. Popov, V.K. Chistov, F.I. Paramonov, and other notable designers of enterprise and industry level automated management systems deserved mention. Currently, there is an extensive expertise in designing of national information systems, the national election automated management system of Russia (GAS Vybory), databases of supervisory agencies etc. As applied to the defense industrial complex, the concept of the infosphere was introduced and considered, in particular in Antopol'sky (2016);

- The area of the formation and support of trading platforms where demand and supply of primary information resources are combined. Usually, such platforms remained incomplete projects, though some of them were custom-made for science parks and innovation clusters (Yegorov, 2006);

- Data processing area, including statistical processing of primary information (Goryainov et al., 2001) and solving uncertainties of primary information (Willink, 2013);

- The area of information protection against non-uniform access, including protection of secrets - be it state, commercial, medical, bank secrets (Gunin, 2008), the Information Safety Doctrine of the Russian Federation adopted by Decree \# 646 by the President of the Russian Federation issued on December 5, 2016, the Federal Law of the Russian Federation \#98-FL "On commercial secrets" issued on June 29, 2004, the Federal Law of the Russian Federation \#149-FL "On information, information technologies, and information protection" issued on July 27, 2006, the Federal Law of the Russian Federation \#5485-1 “On the state secrets" issued on July 21, 1993 etc. Work on users' authorization, database access separation and protocols (Bundin, 2017) are also worth mentioning here;

- The area of organization of intra-corporate alliances, including mesolevel intra-holding infospheres in the shape of information alliances, (Kanashchenkov et al., 2004; 2013);

- The area of military conflict studies, where information is viewed as a factor of military safety or military dominance (Germeyer, 1976; Bodrunov et 
al., 2002; Barynkin, 2000), including that in the context of the Treaties on the Limitation of Strategic Offensive Arms made between the USSR and the USA, work on the conceptualization and implementation of the Strategic Defense Initiatives of the USA. Among other things, it was connected with the conception of unilateral battle contact, as a factor of the mutual understanding of the enemy potential and intentions (here we allude to maximin /minimax strategies of the game theory (Rosin, 1970);

- The cost-effect estimation area of information resources (Naydenova, 2017);

- The area of integrated managing systems focused on shared or juxtaposed control objects;

- The area of viewing the information transparency in terms of competitiveness (Teslya, 2009; Khubiev, 2009);

- The area of the transparency of the markets, including stock exchange transactions and B2B and B2C communications markets (Zhu, 2005). In this area it is necessary to mention the special contribution of Nobel laureates in the field of Economics (2001) Akerlof, G., Spence, M., Stiglitz, J. that have developed methods for the analysis of markets with asymmetric information;

- The area of social partnership, state and municipal management in the conditions of democracy development (Bwalya \& Zulu, 2012).

The result of the effort made my scientists and experts were fruitful and profound findings; however, the issue of formation of a well-developed fullscale infosphere is far from completion, and, probably, from a strictly methodological understanding. As far as one can judge by sources accessible at the Russian State Library or the Library of Congress of USA, the problem of economic information transparency of high technology enterprises as a strictly managerial problem in the area of intellectual management, has not become subject of any comprehensive research; moreover, it remains generally untapped.

Based on many years of extensive practical expertise, we have to admit that the economic information transparency level of the majority of Russian high technology enterprises is currently below optimal. The underlying causes of the problem were:

- At least the areas listed above developed in isolation. As a result, there formed either unreasonable information openness of high technology enterprises, or, vice versa, the enterprises kept their information irrationally closed;

- Empirical methods were predominantly used when designing enterprises, whereas scientific design solutions were generated through consecutive trial-and-error tests, rather than based on scientific validation. Oftentimes, infospheres were and still are adversely affected by designers' obstinacy; 
- Encouragements and disciplinary actions from legislative bodies were slight. Of course, individual legislative and other regulations, information closures and disclosures were imposed. All that, however, was only done locally, unsystematically, and in a manner verging on incompetence. Overall, Russian feasibility studies behind draft bills passed are still far from being profound. Moreover, when enforced, those regulatory statutes were easily distorted or misused.

There are still quite a few areas in which the problem of information transparency is analyzed in various aspects, including, for example, medicine (known problems of disclosure of medical information to patients and their families). It is enough to mention, for example, that when using IGI Global search engines, the user is presented with more than 13,000 links to profile and near-profile publications only within this sphere of publications.

However, the consideration of a number of problematic aspects separately or in a complex is practically not affected, namely: the problems of formalization of the representation of economic information transparency of market operators (unilateral or mutual); the problems of correlation of this transparency with economic conflictology and linking with intellectual technologies of formation of management decisions of operators and issues of justification of the content and level of this transparency.

As a result, the feasibility of projects for formation of infospheres, including the transparency, is not just low or uncertain, but unknown as such, even a posteriori unknown, and, therefore, baffles estimation. Their transparency adoption was sometimes ugly, while the very implementation of those projects produced mixed results, with only few projects being successful. It is a disgraceful state of affairs that most of present-day Russian high technology enterprises have a low level of their internal infospheres, which is essentially an "as is" object with low overall quality estimation alongside their economic information transparency, leaving those enterprises catastrophically unprepared for integration into the global economic infosphere.

Undoubtedly, any attempt to jump on the bandwagon of the globalized postindustrial economy era will most likely result in grave crises and even bankruptcies of those enterprises. This is why we see it indispensable to design and to adopt dedicated managerial innovations to form, to maintain, and to develop an advanced economic infosphere having, among other things, an optimal transparency.

\section{Research Methodology}

The problems of optimization of economic information transparency cover the areas of law, economics, management, informatics, operations studies, and 
mathematical models. Accordingly, both methodological and tool fundamentals of the area must also be essentially interdisciplinary. The research that we conducted, and its findings were presented in this article; we used concepts pertaining to a number of areas, namely, civil law, organizational theory, organizational design theory, system analysis, management theory, information theory, identification theory, and other. Some of the important components of those theories were first introduced or developed by us. Naturally, we also used findings of a number of major scientific and applied projects.

\section{Results}

\subsection{Set of external relations of the enterprise}

Any high technology enterprise, as it operates and develops, continuously and inevitably interacts with its environment (Dmitriev and Novikov, 2018). Please refer to Figure 1 below for a typological structure of linkages of a high technology enterprise, including those being members of the corporate structure.

\subsection{Allocation of enterprise infosphere}

Generally, a high technology enterprise is immersed in two infospheres that are embedded, and communicating via a transparent membrane - the internal and the external infospheres, see Figure 2 below. Here, the internal and the external infospheres are separated by a membrane or a filter that determines the economic information transparency of a high technology enterprise in question. This membrane transforms:

- The "outward" information; thus, the enterprise is an apportioned information donor; here, transparency is principally related to this information flow;

- The "inward" information; here, the enterprise is an apportioning information recipient.

Of course, any information emitted or absorbed by a high technology enterprise may vary in terms of form and content, but it inevitably contains economic information, that is, data that contain cost parameters or data required for economic computations - e.g., deflator levels, tax rates etc. Those parameters are predominantly quantitative and have their respective values.

They may vary in elaboration, be ether quantitative or qualitative (e.g., regular of simplified taxation plan), absolute or relative, vary in values (or even have none) etc. The information may also be either direct or indirect. Net value or the area of key assets - buildings and structures - may be reported. Economic information may be either isolated or range information. Economic information 
transparency is considered as related to those information types. No generally accepted view of the above classifications has formed yet; however, some things have become evident.

\subsection{Structuring project for the development of the infosphere}

It is common knowledge that information is a critically important property object for example, the Civil Code of the Russian Federation, (Kanashchenkov et al., 2013), and a critically important managerial resource (Dmitriev, 2017).

Figure 1. Various principal links of a high technology enterprise with the environment (external linkages)

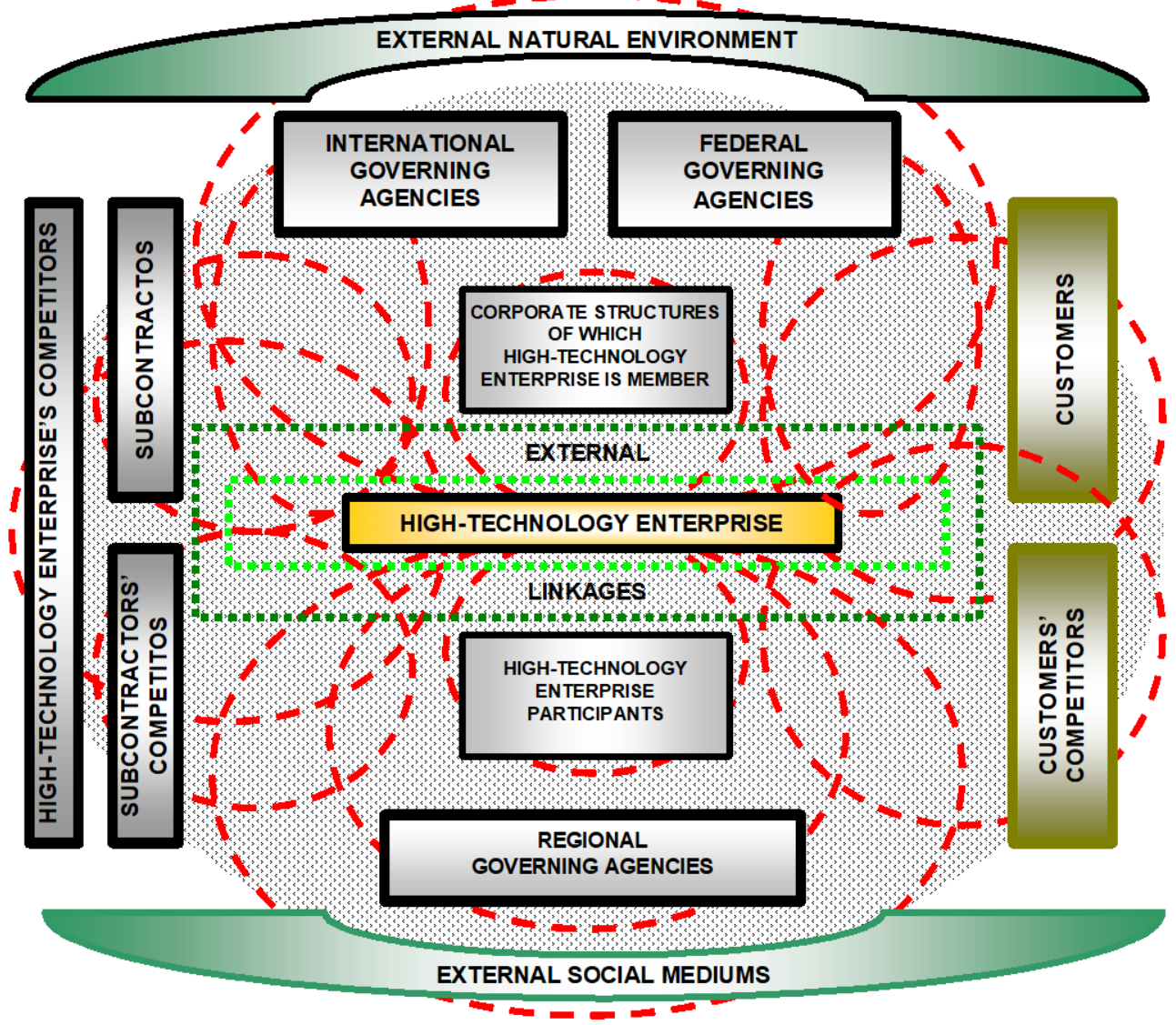

Source: Our own research findings.

Let us consider an overview of an infosphere in a general case, while accepting the description from (Dmitriev, 2005) as a prototype. First and foremost, let us consider the formative structure of an infosphere design project. 
Figure 2. Structure and positions of infospheres of a high technology enterprise

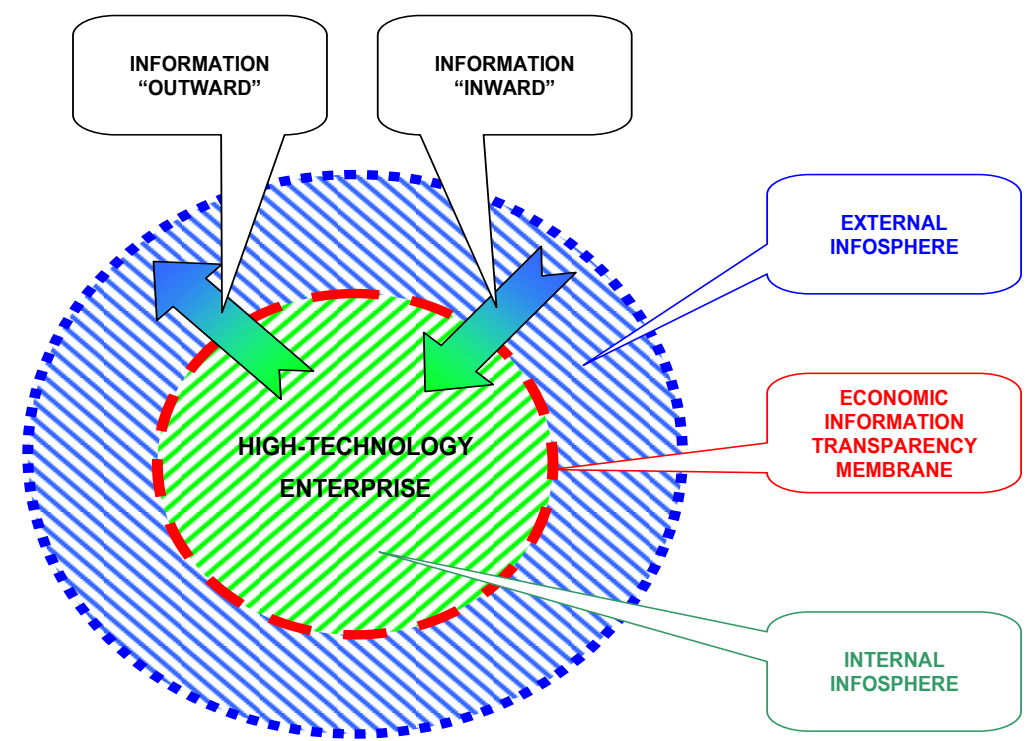

Source: Our own research findings.

Designing of information support of a managerial technology (which is an infosphere in our case) implies solving three principal design problems, namely:

$\checkmark$ External design of the infosphere, or macrodesign;

$\checkmark$ Internal design of the infosphere;

$\checkmark$ Hardware configuration design for the support the maintenance of the infosphere in question. This design, in turn, falls into external design (feasibility studies for the representation, transfer rate, validity etc) and internal design that determines the type and the configuration of a specific hardware and general hardware system to support those requirements.

In this case, an infosphere design is essentially designing a primary data collection and processing system. The external information support design implies:

$\checkmark$ Specifying the nomenclature of the information used;

$\checkmark$ Imposing quality requirements on that data (in terms of their validity, performance, and completeness);

$\checkmark$ Detection of information sources;

$\checkmark$ Specifying supply types of information resources;

$\checkmark$ Specifying price terms and conditions of information resources supplies; 
Imposing certain terms (in particular, those related to copyright, confidentiality restrictions, usage restrictions etc).

Given that the transition of the Russian economy to a full-scale marketeconomy organization pattern is still far from completion, the external information design should also imply the specification of the nomenclature of information sources, including specific document types. In many cases, the external information design also includes representation forms of information filtered and information filtration methods.

We deliberately avoid discussing the latter two factors for two reasons: firstly, being essentially of an advisory nature, managerial information technologies imply provision of initial data viewing to the managerial staff, possibly including the Decision Maker, in practically optional mode or at a preparatory stage to a computational experiment; secondly, output frames and information distortions, including information doublings, losses, character errors etc are very uncommon in an advanced system. The internal design of information support implies solving the following problems:

$\checkmark$ Choosing language means (in a broader sense - software tools) that support the transfer, primary processing, storage, update, and sampling of data;

$\checkmark$ Designing appropriate algorithms for primary information processing, including statistical processing, aggregation, editing, and allocation/sampling, unless the latter can be done by general software tools.

Seeing as the internal architecture (data formats, network protocols etc) of information support of any specific managerial technology must necessarily be compatible with the global information management infrastructure, the latter still being through its formative stage, we find it advisable to utilize:

$\checkmark$ Versatile software that allows both import and export of character information;

$\checkmark$ Algorithms for statistical processing of information and its aggregation.

Design solutions for information support are determined by the factors listed below:

$\checkmark$ The composition of the initial data, which is a list of data required to generate managerial decisions;

$\checkmark$ The form of the initial data, which presets their elaboration degree, data grouping methods, and some of specific properties;

$\checkmark$ The schedule for or the periodicity of presentation or update of the initial data; 
$\checkmark$ The duration or other storage conditions of information received;

$\checkmark$ Validity or uncertainty of the initial data used;

$\checkmark$ Information infrastructure development and maintenance costs;

$\checkmark$ Original information sources - bodies corporate, functionaries, accounting and reporting materials, feasibility studies, and assessments materials;

$\checkmark$ Economic responsibility for maintaining proper function of informational infrastructures.

Streamlined information support in many respects determines an attainable management efficiency level, and, in turn, fully determined by requirements to that efficiency level. Seeing as the incompletion, insufficiency, and belatedness of initial data allow for their reduction to errors when establishing the nature of the management object and the external environment, it is not impossible to introduce their variants to compare.

Information quality improvement costs are related to necessary steps taken to acquire hardware and software to record and to transfer data, their operation, staff training etc. Positive effect of information quality improvement manifests itself as improved quality of managerial decisions ceteris paribus. The pivotal factor here is that the cost and the positive effect are distributed among several persons, which is why initial information quality validation can only be correct if based on final technological-and-economic efficiency criteria - profitability criteria, in particular.

\subsection{Method of the initial data composition validation}

Let us consider how the data composition for a high technology enterprise selfmanagement; in other words, let us consider a method of the initial data composition validation.

The classical and an apparently irreproachable validation procedure for the initial data composition for managerial decisions generation is as follows: all the parameters and all the initial data required for proper operation of function models and algorithms must be known prior to the commencement of computational experiments. In other words, this approach implies that there is a topological accord between the initial data and the files to be defined by computational experiment.

Things are much more complex in practice. Indeed, most of managers in charge of making decisions about legalization of information sources and information transfer liabilities do not take "I-need-to-know-this-for-modeling-purposesonly" argument seriously; rather, they are allergic to it, and they demand for proofs of the need, thus calling into question the very relevance of the model, and, in a broader context - the very feasibility studies method. Paradoxically, 
the demand to reduce the amounts of information flow component is often up for discussion as soon as relevant guidelines and regulations come into effect, while required information is often provided unprocessed, and badly needs semantic processing, and not just formal statistical processing operations. This is why proofs that the existing information exchange practices need improvement have to be furnished, and ways of advancement least painful have to be provided.

Thus, two problems can be formulated for feasibility studies of initial data used can be formulated:

$\checkmark$ The problem of a posteriori (in relation to the design of the management object model and its programming) estimation of sensitivity to the presence or absence of specific initial data. The solution technique is simple and long known. A variety of the problem is a problem to estimate substitution of one initial data with the other if there exist more than one way of substitution or if the data doubles;

$\checkmark$ The problem of indirect data extraction form information used. It is known that those problems are as hard to formalize as they are common.

However, here one has to:

$\checkmark$ On one hand, simplify and ruggedize the infosphere, because some of the important data fail to form here due to faulty bookkeeping and managerial accounting, or irrationally inflated confidentiality;

$\checkmark$ On the other hand, engage in managerially redundant information by force of stereotypes and tradition.

\subsection{Considering of the discrete nature of primary infosphere actualization}

Let us consider how the discrete nature of primary infosphere actualization. It was discussed many times earlier that management systems of a high technology enterprise are either essentially discrete or are artificially made discreet. There exits three ways to establish the discreteness of management, namely:

To accept a periodicity, unreasonably chosen or imposed from within, that may or may not coincide with generally accepted calendar discreteness a month, a quarter, a year etc;

$\checkmark$ Using a minimal technically feasible discreteness;

$\checkmark$ Validation and rationalization (providing feasibility studies) of the discreteness of managements. 
In principle, either constant or variable (adaptive) discreteness can be implemented. The first way, being the simplest of the three, is readily adopted by managerial staffs, while the second one is seen as wasteful, though systems that are founded on "The more often we review the rationality of managerial decisions and readjust them whenever necessary, the better management results are" approach do exist worldwide. This is why we see the third approach as preferable to the first two. There are three aspects to the management discreteness, namely:

$\checkmark$ It is part of information support, as it determines the periodicity of initial data collection;

$\checkmark$ It is part of general management, as costs incurred on initial data collection may form a great deal of production costs;

$\checkmark$ Is in conjunction with research into management system stability, because one can hardly imagine information collection that does not entail conceiving managerial decisions and implementation of managerial actions that come in the shape of organizational, technical and other steps, and is close to discreteness parameters of a management object.

This is why the problem of choice of management discreteness is a complex problem. Nonetheless, it is in tightest conjunction with feasibility studies behind information support. Let us consider the content of an implemented approach to management discretion feasibility studies, isolating two validation stages.

At stage one, primary estimation is done within a framework similar to known approaches to establishing operation periodicity of systems for signal pickup and survey after moving objects.

At stage two, the estimation findings are tested, and, if necessary, adjusted by studies of management system stability, which is done based on status values observed in the system. Stage two is solving an optimization problem where the management system discreteness acts as the optimizing variable and optimality criterion as the optimized variable.

The problems solution is founded on a sequence of custom-made computational experiments on a software-supported management computational model. In practice, the procedure is reduced to study of how a decrease in management discreteness impacts decreases in losses incurred on managerial errors and increased costs of managerial decision-making. It is worth noting that the mathematical model is used dually in this procedure - as both a basis under decision optimization and a simulator of an actual management object. 
This is how the procedure works. First, several variants of management discreteness are compared. Then, for each of those variants, discrete time moments that correspond to the discreteness in question, and calendar periods in-between are studied. Further, for each of those calendar periods, an optimal and a rational managerial decision are found from the optimality criterion.

Then, the dynamics of the management object is duplicated under the conditions of its implementation. In principle, the above can be done as a part of a series of recurrent computational experiments, while estimating forecasted values of the object state under the conditions of modeled implementation of the managerial decision. The criterion for the choice of preferable managerial decisions is totally identical to the criterion found when modeling the object state dynamics under the managerial decision implementation conditions. At the end of a calendar period that closes a forecast horizon, the analyzed, that is, the last variant is compared with that was found to be dominant in previous iterations, and then the best one is chosen from either. If a preset limit of variants or computational experiment has reached its ceiling, then there comes a cessation; if not, then another variant is analyzed according to a chosen strategy of assignment or enumeration variants, and then the procedure goes on as described above.

It is noteworthy that a case of irregular sampling of the calendar time axis is in accord with the framework of the above procedure. We do not rule out a possibility that unique values of management rational discretion will be found for some managerial decision categories.

Research suggests that the discreteness of infosphere's actualization (implementation) must be minimal, which means it should be confined to a real or a subreal time scale. The actual dynamics of managerial life, however, suggests that the day-week discreteness is acceptable. Besides, it is advisable to implement several discretenesses - per each initial data category.

\subsection{Requirements to the primary information quality}

Let us formulate requirements to the primary information quality, that is, the content of the primary internal infospheres. Let us discuss a method that allows to make valid decisions about requirements to the fullness and validity of initial data, and necessary steps to be taken to change them.

A great deal of components of information improvement costs is of a simultaneous nature and is relatively easy to calculate. This applies to operation support of an information system, unless the costs do not depend on the good state of the transport inventory, otherwise the calculations must be linked to relevant events. 
Taking into account the reciprocal influence of the quality of various information data categories may be of help when solving the problem in question, estimating the efficiency of nontrivial ways of data procurement, and finding ways to enhance the data elaboration. The application procedure of the method is as follows:

A data list (initial data types) is set, and then the data is subjected to comparative estimation $\mathbf{I}_{\mathbf{1}}, \ldots, \mathbf{I}_{\mathbf{n}}$. Let the data list setting accuracy be determined by $\mathbf{P}_{1}^{1}, \ldots, \mathbf{P}_{\mathbf{n}}{ }_{n}$ for the first variant of information support implementation, and by $\mathbf{P}_{\mathbf{1}}{ }_{1}, \ldots, \mathbf{P}_{\mathbf{n}}{ }_{\mathbf{n}}$ for the second one, where $\mathbf{P}_{\mathbf{i}}{ }_{\mathbf{i}}$ is the parameters of error of the \#-th variant for the $\mathbf{i}$-th data type. The value $\mathbf{P}_{\mathbf{i}}^{\#}$ may set the maximum absolute mean error, the relative mean error, the border of the centered confidence interval etc. The above formalization also applies to cases when data uncertainty, not data validity, is to be considered. Let the one-off costs be known for both variants of information support implementation $\mathbf{C}_{\text {actual }}^{\mathbf{1}}$ and $\mathbf{C}^{2}$ actual.

The problem is considered for a certain group of managerial decisions $\mathbf{U}_{\mathbf{1}}, \ldots$, $\mathbf{U}_{\mathbf{m}}$. A gain from the "best-case" damage from error on $\mathbf{I}_{\mathbf{1}}, \ldots, \mathbf{I}_{\mathbf{n}}$ is found. To do that, a baseline value of the $\mathbf{B}_{1}, \ldots, \mathbf{B}_{\mathbf{n}}$, is chosen, which should be the same for both variants. Based on the values $\mathbf{P}_{1}^{1}, \ldots, \mathbf{P}_{\mathbf{n}}{ }_{\mathbf{n}}$, and $\mathbf{P}^{\mathbf{2}}{ }_{\mathbf{1}}, \ldots, \mathbf{P}_{\mathbf{n}}{ }_{\mathbf{n}}$ set, the absolute mean errors of the initial data are found:

$$
\begin{aligned}
& \mathbf{M}_{\text {left" }}^{\{\}_{1}}=\mathbf{B} * \mathbf{P}^{\{\}_{*}} ; \\
& \mathbf{M}^{\{\}_{\text {right }}}=\mathbf{B} *+\mathbf{P}^{\{\}_{*}} \text {. }
\end{aligned}
$$

Here, the characters "+" and "-" of the shift operation essentially generalize of the operator that shifts either right or left. Then the complete extreme experiment plan is built as:

$$
\mathbf{X}^{\left\{{ }_{1}\right.} \times \mathbf{X}^{\}_{2}} \times \ldots \times \mathbf{X}^{\{\}} \text {; }
$$

where $\mathbf{X}^{\{\}_{*}}$ are either $\mathbf{M}^{\{\}_{\text {left*or }}} \mathbf{M}^{\{\}_{\text {right* }}}$, with optimal managerial decisions found through $2^{\mathrm{n}}$ experiments.

$$
\left\{\mathbf{U}^{\}}{ }_{1}(1), \ldots, \mathbf{U}^{\}}{ }_{m}(1)\right\}, \ldots,\left\{\mathbf{U}^{\}}{ }_{1}\left(2^{\mathrm{n}}\right), \ldots, \mathbf{U}^{\}}{ }_{\mathrm{m}}\left(2^{\mathrm{n}}\right)\right\} .
$$

Consequences $\mathbf{E}^{\{\}}(\mathbf{1}), \ldots, \mathbf{E}^{\}}\left(\mathbf{2}^{\mathbf{n}}\right)$ of those managerial decisions in the shape of cumulative losses and damage are estimated through the next $\mathbf{2}^{\mathbf{n}}$ computational experiment, for which the baseline values $\mathbf{B}_{\mathbf{1}}, \ldots, \mathbf{B}_{\mathbf{n}}$ are set on the inputs $\mathbf{I}_{1}, \ldots, \mathbf{I}_{\mathbf{n}}$.

All in all, it takes $\mathbf{2}^{\mathbf{n}}$ basic and $\mathbf{2}^{\mathrm{n}}$ extreme or near-extreme experiments to find the above. The "best-case" damage is found as shown below: 


$$
\begin{aligned}
& \mathbf{Y}^{\{\}}{ }_{\text {best }}=\mathbf{C}^{\{\}} \text {actual }+\min \left\{\mathbf{E}^{\{\}}(\mathbf{j})\right\} \text {, } \\
& \mathbf{j}=\left[1,2^{\mathrm{n}}\right]
\end{aligned}
$$

while the "worst-case" damage is found as

$$
\begin{array}{r}
\mathbf{Y}_{\text {worst }}^{\left\{{ }_{\text {to }}\right.}=\mathbf{C}_{\text {actual }}+\max \left\{\mathbf{E}^{\{\}}(\mathbf{j})\right\}, \\
\mathbf{j}=\left[\mathbf{1 , 2} \mathbf{2}^{\mathbf{n}}\right]
\end{array}
$$

Then, the "best-case" damage gain is:

$$
\mathbf{D}_{\text {best }}=\left|\mathbf{Y}^{2}{ }_{\text {best }}-\mathbf{Y}^{1}{ }_{\text {best }}\right| \text {, }
$$

and, for the "worst-case" damage

$$
D_{\text {worst }}=\left|\mathbf{Y}^{2}{ }_{\text {worst }}-\mathbf{Y}^{1}{ }_{\text {worst }}\right| \cdot
$$

This case highlights a pronounced dissonance between feasibility studies findings and the way things stand in reality. The estimations found suggest that the relative mean error of the initial data should not exceed 3 to $5 \%$. The above error is always safeguarded when preparing accounting balance sheets; however, a vast majority of forecast parameters contains substantially higher inaccuracies. This is why making every effort to verify and to specify initial data to make managerial decisions is the only solution to the issue.

\subsection{Commodity interpretation of the primary information resources}

Now let us make a commodity interpretation of the primary information resources. Seeing as supply models and demand models are of a mixed subjectobjective nature, the problem of obtaining initial data is a special problem that has both a subjective and an objective aspect. There exist two legitimate approaches here:

$\checkmark$ Obtaining initial data independently, including obtaining data by selfassessment;

$\checkmark$ Buying data available on the information market.

Either way, information is property (a property object), normally a commodity sold at a price. Russia's transition to market economy opened new opportunity and new potential problems. Indeed, owners of information resources are entitled to payments for the information they are able or bound to collect, to process, and to present. It is reasonable and advisable to organize separation of duties for information presentation, in particular, for submitting statistical reports as a part of government contracts that receive relevant funding. 
Besides, information to be considered is only good when used as a whole; that said, any prices imposed on any individual information components, and not on information packages, may lead to partial failures, thus gravely depreciating the information that has been delivered and paid for. Situations when a commodity information supplier may, on account to his/her interests and business independence, unilaterally curtail or stop information supplies, thus bringing management to a halt, also occur.

The advantages of the adoption of economic management methods include a potential possibility that there will be no reasons behind massive information secrecy or distortion, and highlighting the problem of procurement and usage of information resources. Thus, information has both of the properties of a commodity: it has a cost in use (being useful) and a cost (the value of money and labor used to produce it). Information and material objects have both shared and distinguishing properties. These information objects have the following in common with products and material resources: they are in demand; they are property, which means they can be owned, used, and sold; they have specific designers (and suppliers); they have a cost and a price; and they can be supplied subject to specific terms and conditions.

However, information resources and other transferable/tradable objects have a number of fundamental differences, among which there are:

$\checkmark$ Unlimited replication, which implies objects' preservation and unlimited sales;

$\checkmark$ Practical indestructibility;

$\checkmark$ Having to be tailored to specific users' conditions (with few exceptions);

$\checkmark$ Obligatory author's supervision of objects supplied, including those related to implementation;

$\checkmark$ A possibility of various restrictions on both usage and secondary replication;

$\checkmark$ Difficulty tracing copyright and supplier right compliance;

$\checkmark$ Multiple doubled objects. In sharp contrast to material products samples that can be put to similar use, information may interpret the reality in more than one way. Several versions of final information can be offered on sale;

$\checkmark$ Benefits from indirect information. Information that there exists certain information, often sells at a high price;

$\checkmark$ Depreciation through trial use. Indeed, it fair to decline an offer of sale if some of the data just viewed are unusable; however, it is nearly impossible to make yourself forget or to abstain from using any reliable data from the offered ones;

$\checkmark$ Unpredictable quotations of prices. While quotations of prices of material products may fluctuate within somewhat a limited range (it is 
hardly ever possible that demand may emerge or disappear in an instant), prices of information (but not of a technology) may slump to zero instantaneously;

$\checkmark$ Possible sharp antagonism, and not just competition. Offered in the market, newer information may render older one totally outdated;

$\checkmark$ Uncertainty of some of or all of consumer properties;

$\checkmark$ Extremely easy transfer and no damage in transit (or, in this case, no damage in transfer);

$\checkmark$ No wear and tear, only obsolescence or outdating within a fixed or uncertain time period;

$\checkmark$ Instantaneous data transfer to an end user and a possibility of receiving a response after a vanishingly short time span;

$\checkmark$ Sometimes unclear supply deadlines if information is communicated via the Internet;

$\checkmark$ Constant readiness for supply;

$\checkmark$ Multidimensional consumer properties, including operation properties;

$\checkmark$ Poorly identifiable suppliers of information data and technologies, as well as information sources and information components used;

$\checkmark$ Confidentiality for both the seller and the buyer of the data and technologies, as well as the very fact of a sale, whether successful or failed.

Thus, information is (or, rather, it should become in Russia) subject to marketing transactions, with its supplies fully covered by contracts. In sharp contrast to material products, information supplies are practically instantaneous and safeguard a close integration of the management systems of the counterpart enterprises. As any other contracts, terms and conditions of information resources supplies require profound feasibility studies, including substantiation of prices.

\subsection{Estimation of cost characteristics of information resources}

The problem of estimation of cost characteristics of information resources, generally, within the area in question - the Intellectual Property (or otherwise Ownership) Assets (IPAs) area - existed and was solved methodically under the administrative command system in the USSR, and persist now, under market economy, or transit to market economy. The administrative command system set an unambiguous pricing procedure, where only the net book value and the depreciation cost of the IPAs were fixed, both being purely for accounting reports.

The net book value was determined by the estimated cost or the list price, fixed in a centralized manner, or stipulated in a supply agreement, but also fixed in a centralized manner. The depreciation cost implied a reduction in the original cost - the balance value, with a gradual decrease dynamics calculated based on 
a conventionally fixed deadline, which means that the depreciation cost was supposed to slump to zero past the deadline (the original cost less accumulated depreciation).

Similar practices survived the transit to market economy and still persist, though revaluations were (and still are) of a predominantly inflation nature and done purely mechanically - all assets and their deflators inadequate to the actual inflation rate were revaluated. There were no (and still are no) dedicated estimation methods other than bookkeeping - the Russian intellectual property assets market is still in embryo for one thing.

It is noteworthy that under market economy, there exist net book value, depreciation cost, disposal value, and replacement cost, with "net book value" becoming synonymous to what was previously referred to as "deprecation cost". However, we use the old term as more meaningful. Net book value is the same as disposal value the moment when intellectual property assets are being created; nonetheless, a costly method that equates net book value with costs actually incurred on creation of assets is still used. Depreciation cost is found from the same procedure - as percentage of the net book value parameterized by a depreciation deadline (the original cost less accumulated depreciation). Net book value is currently interpreted as being synonymous to deprecation cost while replacement cost is a cost incurred on restoring the IPAs (object) to their original state.

Managerially and economically, net book value and depreciation cost are of little significance; rather, they pertain to accounting formalism. Estimation of disposal value interpreted as the bid price of respective IPAs is an actual problem. Replacement cost is normally equated with disposal value. Here, we can make reference to a number of standardized pricing methods.

However, they are about calculations of the cost price; therefore, the finding an answer to the question about net book value is the most one can make of those methods.

So, let us concentrate on the expertise in estimating depreciation cost as the object's price. Generally, it is fair to assume that the depreciation cost should not be lower than the disposal value, nor should it exceed the bid price. However, while any bid price is a stringent limitation, any depreciation cost is only a ballpark figure. Let us consider methodical approaches to evaluation of IPAs.

In Russia's domestic market, IPAs are an idiosyncratic kind of goods to be used under nontrivial conditions, to which we made a passing reference earlier. Moreover, the very Russian economy has idiosyncrasies, among which a striking difference between living standards is and outside of Russia, no social 
mobility of workforce, and limited convertibility of the national currency worth mentioning; besides, respect of and compliance with copyright is somewhat complicated in our country. All of the factors listed above, engender an idiosyncratic pricing of IPAs for Russia's domestic market. Prices of IPAs are set on a "supplier's identity - customer's identity " basis; however, the above principles are also true for most information resource types. Let us analyze the existing practices. It is fair to isolate three situation types here, namely:

- Situation 1 for imported IPAs;

- Situation 2 for IPAs produced and consumed by domestic enterprises;

- Situation 3 for IPAs produced and exported by domestic enterprises.

Situation 1 implies seven pricing options for imported IPAs:

1) Duplication of "Western" prices in a Fully Convertible Currency (FCC), normally plus distributor/dealer margin. The latter, from here onwards, may principally come in three shapes: "good connection" payments (bribes), payments for Russian version of IPAs, or both;

2) The two previous options, with the final price converted into rubles, using a conversion rate close to the fixing rate;

3) An option that combines the above two;

4) Setting a price the buyer is certain to accept;

5) Barter where the initial price is a benchmark for the equivalence of exchange;

6) Selling IPAs as part of a set, without the buyer knowing how much of the set's total price is the IPAs' price;

7) Setting a price, based on the IPAs' economic benefit to the buyer.

The latter two options conventionally have three payment options: a FCC, Russian RUB, or FCC+Russian RUB.

The first two options of Situation 1 are typical of direct sales by designer companies, joint ventures, or official distributors/dealers. However, options one and three are not taken seriously by domestic enterprises that have no FCCs at their disposal or are unwilling to exchange "real" money for "intangible" IPAs, even if the latter come in the shape of equipment, desirable consumer goods, or pay rises tangible even to unqualified staff. The above is also true for options six and seven. Option two is used most commonly, even though it puts obstacles in the way of even major domestic enterprises.

Options four and five are commonly used by "pirated" private businesses; now that foreign companies are expanding to the Russian market where increasingly stringent supervision over copyright law compliance is being enforced, they are most likely to become a thing of the past due to a barrier to sales of IPAs that contain "unofficially borrowed" components. 
Option six is a practice peculiar to Russia, which is selling of a "prefabricated" set of equipment and intellectual components, meant to disguise and to legitimize middleman margins on imported products. With further advances in tendencies towards openness of the domestic market and diversification of international traders, this option is cosigned to oblivion.

Option seven was seldom used, seeing as an overwhelming majority of domestic end-users of imported IPAs are arm industry enterprises, and relevant analytical reports were physically inaccessible to foreign companies and their distributors. However, massive conversion of defense factories and abandoning the practice of unreasonable secrecy open immense and promising opportunity for activities here; yet, with more and more domestic enterprises coming under sanctions, this option may become common.

Option seven may be also uncommon for imported IPAs due to the established import structure: major imports into Russia include programming software tools, general software, and software shells - that is, software that does not impact the management end efficiency, or, at least, the impact in question cannot be isolated.

Situation 2 - for an area which is the same as the country where the IPAs are manufactured and consumed - implies implementation of one of the five pricing options below:

1) prime cost-plus-pricing calculation. Taking into consideration the monopolization of domestic developers, a prime cost in our country is equaled to particular manufacturer's (supplier's) expenditures. Prime cost components consist of personnel labor costs, overhead expenses, depreciation charges, etc. A fixed profitability level and specific taxes shall be properly assigned and stated throughout the cost-to-pricing process. Such option is typically adopted for nonprofit R\&D units with charges splittable down to particular clerk salaries. This is a clear pattern of the cost-specific mechanism, IPAs nonreplication orientation and degeneracy of administrative principles to result in actually ritual document-creation work since this kind of calculation gets selfadaptive to any customized financial resources.

2) setting a price to be "reasonable for a customer". Despite its market image the option has shortcomings only. In the first place, it would hardly cover developer expenses for high-cost projects; in the second place, there is a wide and non-motivated spread of prices to cause a negative customer's reaction to excess payment comparable with other ones; in the third place there should exist a price variation reference point; and so on. The only but doubtful benefit is to have the possibility to get at least some returns on IPAs items. As a matter of fact, the option concerned can be referred to the events when forged IPAs items have to be sold or developer finds himself/herself in a desperate financial situation. In any case, the proposal based on "as much as you give" principle is 
a definite sign showing that a customer should be very careful to avoid trapping.

3) analogy-based estimation. This option is commonly used but preferable for moderate, simple and typical IPAs items. The main problem is that a range of user-defined IPAs characteristics is matchlessly richer than those in technical items and, therefore, it fails to be compared. Respectively, spread of supply prices for said typical projects makes up sometimes the established procedure.

4) charging a price on the assumption of an IPAs application effect the customer can be exposed to. This option is uncommon for the domestic practice (mostly, the developers are not likely being ready or capable to qualify several categories of potential customers); complex.

5) fixing a price of domestic IPAs items supplied in scope of a certain

All options for situation 2 are typically featured with orientation to sales in Russian rubles only. There is no information about any domestic IPAs sale proposals to our enterprises at free currency exchange rates and the matter probably reflects developers' real state of affairs. Exchange deals are occasionally made by individual persons only.

As for situation 3 (for exported domestic IPAs items), it is also actually notable for practical options, in particular:

1) converting a domestic currency price in RUB to free currency at the auction market exchange rate. This method creates a miserable price that will be valued in the global market as a dumping one or will indicate that the product has low quality;

2) converting a currency price in RUB to US\$ through developers' salary. Today, the matter can be viewed differently from another extreme angle - overpricing caused by poor productivity of domestic developers' labor (due to deficiency of technical facilities, nonproductive diversions);

3) selling for a knock-down price at free currency exchange rates;

4) selling abroad at some uncertain price in rubles which is considered by developers as reasonable (e.g. with the belief that this price "will be enough for buying a car");

5) selling at a price incorporating customer use efficiency;

6) IPAs assessment in comparison with foreign equivalents;

7) pricing as a foreign distributor's profit share.

Taking into consideration the deficiency of information among domestic developers about global market prices and companies' practices, the last two options have not been actually used. Considering the above comments, other options are highly valued. Besides, one cannot but think that all exported IPAs items virtually need further "west-adaptive" refinement at least relating to spelling, networking orientation, certification etc. 
The last two situations can demonstrate that a customer-supplier relationship form has a tremendous effect on the level of supply prices. Indeed, the current economic and legal situation prevailing in our country gives rise to multiple IPAs supplier-customer relationship forms being developed across various enterprise types. And they, for their part, significantly govern IPAs pricing.

Price formation in the internal IPAs market is substantially affected by such factors as economic instability and ambiguity which are expressed in uncontrolled and low-predictable inflationary processes, delays in payments, customer withdrawal from contracts frequently occurred due to deterioration of a financial state and inability to cover an executed portion of the IPAs development project.

As evidenced by the foregoing, the following approach to pricing of IPAs items either created or operated in the internal market seems to be of preferential nature. But this is to say that the approach concerned applies to IPAs suppliers (supply price) and customers (demand price).

First of all, we should mention that in contrast to technical products and to practically any type of scientific-technical services both the demand and supply pricing stated in single acts of sales can be found below the prime cost of production for non-unique (i.e. subject to replication) IPAs items. Therefore, when charging a price, to a greater extent for those products other than the technical ones, the amount of IPAs sales (expected or actual IPAs issue) must be known. It is necessary to draw particular attention to the feature which relates IPAs items with some non-essential goods. There is inverse recursive volume of sales- to- price relationship. In this case, the only way out is transition from one-dimensional price-specific space to two-dimensional space "quantity of copies sold - price of one copy".

In case of a unique IPAs nature, the following fixed approach can be used. This approach assumes estimation of a prime cost and effect followed by finding a compromise point within the related range. In this situation, a prime cost acts as a lower supply pricing boundary and an effect - as an upper demand pricing boundary. Should a developer have every reason to believe that it is possible to sell several copies or functional versions, he/she should solve four subtasks:

$\checkmark$ to estimate an expected or actual IPAs development prime cost including replication and follow-up procedures depending on weather the price is assigned for finished IPAs items or items under development);

$\checkmark$ to estimate an expected economic effect for each of potential customers;

$\checkmark$ to estimate amount of funds potentially granted by enterprises for procurement of IPAs items. It should be noted that such problem is 
peculiar just for domestic enterprises that traditionally suffer complicated financial position and that are limited in purchasing and application for loans activities due to objective and subjective reasons;

$\checkmark$ to fix a price for a particular sale operation taking into account earlier and other IPAs sales expected in the market.

If an enterprise buys IPAs items, a declared seller price may be used as an upper supply pricing boundary, other than prime cost estimation. Venture character of the demand makes us to take into account a comparatively overstated supply price. Similarly, it is rationally to make an orientation aimed at the left-side confidence interval boundary for estimating an economic effect and, accordingly, an understated demand price, thereby in total to narrow a range of searching of compromise price solution to a particular extent. If costspecific characteristics are stated in different currencies while fixing a price, they shall be converted to a unified scale to be oriented to payments made in the IPAs currency and on the IPAs conditions.

Generally, an IPAs buyer should solve nearly the same problem but with the IPAs pricing minimized. Naturally, when selling (buying) IPAs items with distribution right it is necessary to bear in mind increase in sales or, on the contrary, appearance of competition in the market sector accessible to a seller and a buyer.

Such approach is undoubtedly featured as more common than that guided by the applicable regulatory and methodical documents made for calculating the IPAs development prime cost and for proceeding to a price using the profitability standard. Additionally, some prime cost-structuring recommendations may also be used. However prices are defined in other documents as contractual ones, thus being in conflict with the mentioned priceto-cost relation.

Problems arising out of IPAs development prime cost calculation are labor and resource costs expected when setting a price of IPAs items, whether undeveloped or finished. Moreover, that problems are induced either by forecasting such costs or, actually, by diversifying research results. In the first case the trouble is caused by the forecast estimate and in the both cases - by specific IPAs cost identification.

Experimental-statistical standards are mostly applied for forecasting. They are simulated as regression patterns for sampling developed IPAs data. The main disadvantage of such methods is orientation solely to approximately standardized developments. The following advanced models for IPAs demand price estimation should be applied:

$\checkmark$ IPAs design, production and technical maintenance; 
$\checkmark$ design, production and technical maintenance of the commodity in which IPAs items are applied (included or used );

$\checkmark$ industrial and economic activity of IPAs suppliers and customers.

If to look at special conditions, the matters pertaining to confidentiality must be primarily pointed out. The set of problems of the internal infosphere design is omitted since it has to be studied individually. Currently, the infosphere often makes up particular information media for example, Internet Environment, other than a totally integrated structure.

\subsection{Inducing transformation of information by transparent membrane}

Transparent membrane-induced transformation of information may have the following effects:

$\checkmark$ partial removal of information;

$\checkmark$ partial corruption of information;

$\checkmark$ partial delay of information.

Commonly, the ratio is stated within the range of $0 \%$ to $100 \%$. Any high-tech enterprise can be identified as information-transparent in full at $0 \%$ and nontransparent in full at $100 \%$.

It is clear that a option of complete corporate non-transparency of a high technology enterprise should be totally removed from the applied, nonabstractive analysis since any enterprise, at least in the latest Russian situation, cannot but is rather liable to submit its internal information (e.g. tax statements), to use banking services, to pay wages to employees, to order and to supply products etc.

\subsection{Subjects of information transformation}

Transformation capacity of the information that leaves any high-tech enterprise (i.e. economic information transparency) can be typically governed, at least, by the following entities:

$\checkmark$ high-tech enterprise administration (first of all - the Directorate);

$\checkmark$ enterprise members - introducing corporate codes, making decisions at meetings and at special boards like boards of directors;

$\checkmark$ regulating bodies including legislative authorities. There are regulations that lay down specific international non-proliferation rules (for example, manufacturing and using weapons of mass destruction and space vehicle processing facilities). 
With an internal company management system selected to achieve the research purpose, we can leave a superior executive board of a high-tech enterprise only employed as a managing agent - to be conditionally called a high-tech enterprise management.

\subsection{Impact of economic information transparency of a high-tech enterprise on its condition and results}

Let's look at how the information transparency of a high-tech enterprise in economics influences its state and results. We should note that no direct influence on the above high-tech enterprise is exerted in all cases when the transparent membrane penetration behavior is changed. Thus, the transparency has its influence on the following:

$\checkmark$ content and pricing of core information if the latter is an item commercially produced by a high-tech enterprise;

$\checkmark$ enterprise good standing image that could hardly be projected on any area of economics;

$\checkmark$ state and local public authorities as referred to a hard-to-estimate economical factor;

$\checkmark$ managerial decisions made by market operators regarding a high-tech enterprise.

Market operators to be taken into consideration under the study are recipients of high-tech enterprise-specific economic information that penetrates through a transparent membrane, namely:

$\checkmark$ competitors;

$\checkmark$ potential customers of marketable products;

$\checkmark$ potential suppliers of resources and marketable products (commonly partners - production partners, banks, insurers, stock investors etc).

Depending on the rate of the high-tech enterprise information transparency in economics they are capable to take managerial decisions about that enterprise that have different orientation and failure levels including:

$\checkmark$ favorable and unfavorable decisions against positive (friendly) intentions presented by information recipients;

$\checkmark$ favorable and unfavorable decisions against negative (hostile) intentions presented by information recipients.

Accordingly, a subject of study and management shall also include:

$\checkmark$ a high-tech enterprise;

$\checkmark$ its information and contractual partners. 
As a matter of fact, this enterprise group can simultaneously establish both contracting and conflict spaces. Economic- and information-based conflict situations can occur within the bounds of the latter space. Such kind of a group of information-coupled contractors can be interpreted as an information-based pceudo-corporation (Dmitriev and Novikov, 2017).

\subsection{Optimizability of economic information transparency of the enterprise}

Now, we will try to settle the matter whether it is conceptually possible to optimize the rate of high-tech enterprise information transparency in economics.

In the first place, as it has been previously shown regarding the quality, the rate of high-tech enterprise information transparency in economics has its significant effect on the corporate state and resultant capacity - i.e. certainly on the performance and managerial decision optimization criteria.

In the second place, high-tech enterprise information transparency in economics is varied as a result of exposure to managerial effects - i.e. enterprise management procedures and measures.

In the third place, influence of any managerial decisions on state performance can be certainly traced since such prognostic estimation problems have been analyzed and studied.

Accordingly, high-tech enterprise information transparency in economics is capable to be successfully optimized.

\subsection{Tools for substantiation of decisions on economic information transparency of the enterprise}

Recommender DSS is to be used for its management, as an object of management is rather complicated and critically important (Dmitriev, 2005). Special management is implemented, based on a three-stage scheme that implies the following:

$\checkmark$ conceptual formulation of a managerial problem (task);

$\checkmark$ formalization of the managerial task;

$\checkmark$ solving the managerial problem.

Please refer to Figure 3 to see the conceptualization of those three stages. When formalized, managerial problems are scalarized and determined conditional optimization problems, with their target function set by a mathematical model of the management object. To secure proper function of a managing system, some of the blocks (namely, the estimation block, the forecast block, the 
analysis block, and the optimization block) must be linked to their intellectual core - a mathematical model of the management object (Dmitriev, 2002; Bodrunov et al., 2003). Accordingly, information pseudo-corporation is object to modeling (see Figure 4) together with a set of mathematical algorithms.

When formalized, managerial problems are scalarized and determined conditional optimization problems, with their target function set by a mathematical model of the management object. To secure proper function of a managing system, some of the blocks (namely, the estimation block, the forecast block, the analysis block, and the optimization block) must be linked to their intellectual core - a mathematical model of the management object (Dmitriev, 2002; Bodrunov et al., 2003). Accordingly, information pseudocorporation is object to modeling (see Figure 4) together with a set of mathematical algorithms.

\subsection{Localization of a new area of research - economic information conflictology}

It seems that the considered problem management situations and discussed the problems of research in relation to economic information transparency allow us to state the validity of the localization of such areas as the hybrid area of economics, conflictology and informatics, economic information conflictology. It should incorporate a well-known area of economic information security in relation to the economy.

\subsection{Testing of development}

The results of economic information transparency designs for high technology enterprises have proved successful through test and adoption on a large scale and throughout long periods. In particular, they were used: 
Figure 3. System technology stages of managerial decision formulation
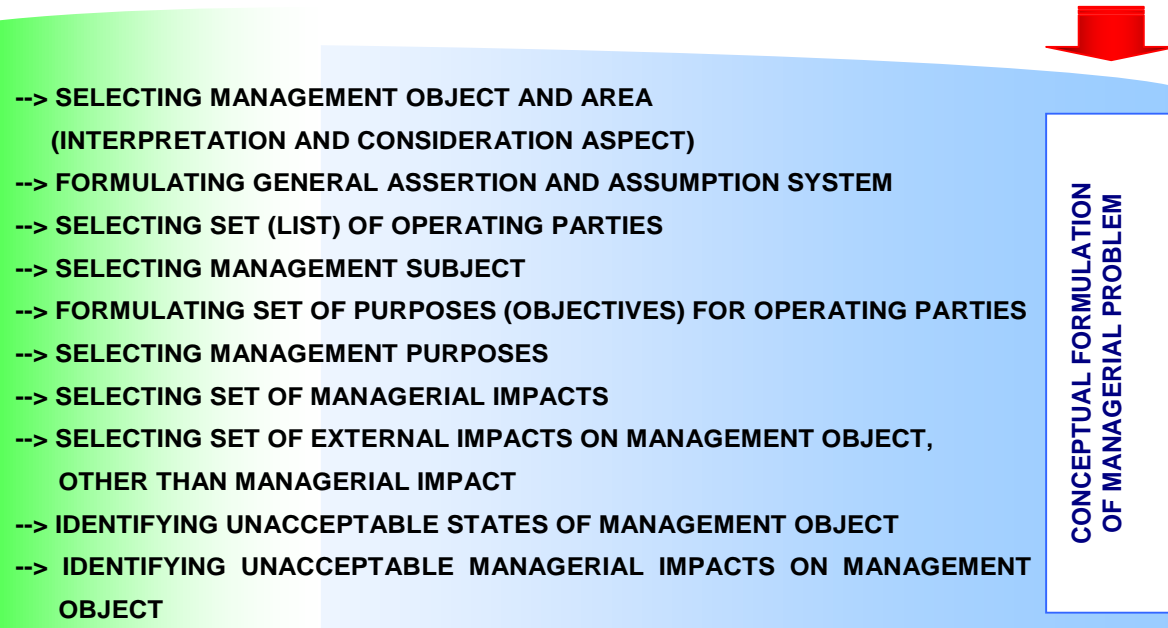

--> FORMULATING MANAGERIAL INFORMATION TECHNOLOGY REQUIREMENTS

--> SELECTING MANAGERIAL INFORMATION TECHNOLOGY FROM AVAILABLE ONES OR CREATING NEW ONE UNLESS ACCEPTABLE ONES ARE AVAILABLE

--> COLLECTING INITIAL DATA

--> IMPLEMENTING MANAGERIAL INFORMATION TECHNOLOGY

Source: Our own research findings. 
Figure 4. Management object and mathematical toolkit structure

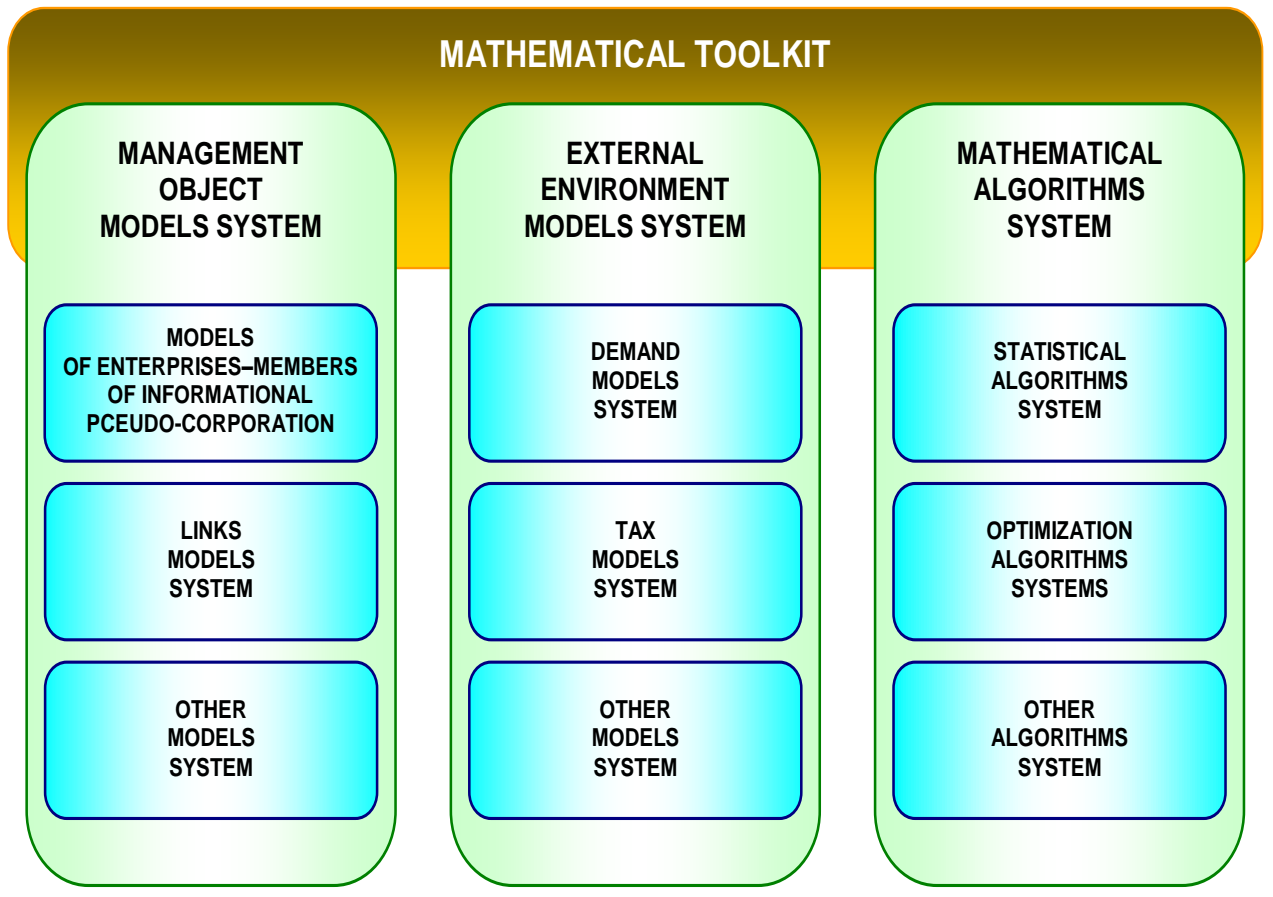

Source: Our own research findings.

$\checkmark$ For the design of the cross-industry (the aviation industry of the USSR - the civil aviation of the USSR) automated system for the collection and exchange of data about the status of aviation inventory ordered and supplied to enterprises of the above two industries, adopted in 1984;

$\checkmark$ When doing a work package to design long-term and middle-term projects for supplies of all types aircraft engines and expensive components to maintain the normal operation of the aircraft fleet of the civil aviation of the USSR between 1984 and 1996 with regard to the collection of data as to the status of aircraft and their components;

$\checkmark$ For inspections of subordinate enterprises carried out by the staff of Ministry of Aviation Industry of the USSR to monitor their status and adoption of technological innovations between 1985 and 1992;

$\checkmark$ For original software tools for the finished product and component inventory simulation, designed and supplied by us between 1986 and 1992, for the customers to choose between an open-source and a closed-source version;

$\checkmark$ For the design of incorporation projects for a number of aircraft industry enterprises and enterprises of some other high technology complexes and industries in Russia between 1996 and 2002 to find out their actual status; 
$\checkmark$ For the preparation and appraisal of a number of bills and other federal regulatory statutes covering the Russian infosphere between 1992 and 2002;

$\checkmark$ For the preparation, appraisal, and implementation monitoring of a number of federal purpose programs covering high technology manufacturing enterprises of Russia between 1996 and 2018.

The above expertise was generally positive, with our design concepts included in a number of official guidelines and R\&Ds, the results of which were accepted by customers.

\section{Conclusions}

Based on the research results, we have every reason to formulate the following principal statements, conclusions, and suggestions:

1) Clear signs of imminent globalization and postindustrialization of high technology manufacturing enterprises can be currently observed, which inevitably entails their integration in local and global infospheres. When subjected to decomposition, those areas allow to isolate economic infospheres.

2) Laborious scientific research, including that directly or indirectly related to economic information transparency of high technology enterprises was conducted beginning from at least as far back as the 1940s. However, no scientific solution to the problem of optimal economic transparency of high technology enterprises was found; moreover, only particular aspects of the problem were considered as an empirical issue. That was why we failed to find any full-scale prototype to our design.

3) A high technology enterprise is both a donor and a recipient of heavy flows of various information - directly or indirectly economic. Information is both a commodity and a managerial resource.

4) Economic information flows are essentially flows in discrete time; in a general case - with changeable discreteness.

5) The internal and the external economic infospheres of a high technology enterprise communicate. However, they are separated by a transparency membrane that modifies incoming and outgoing information flows in terms of their completeness, reliability, and relevance. The transparency in question is primarily related to information transformation as it transcends from the internal infosphere into the external one.

6) Economic information transparency of a present-day high technology enterprise significantly influences its own good standing and performance including economic ones, engendering impact on tendencies and failures in managerial decisions made by counterparts and counteracting parties.

7) Economic information transparency of a present-day high technology enterprise is optimizable due to the above influence, transparency variability, and availability of tools to assess variants' statuses and performance. 
8) A DSS, a recommender system, should be used to safeguard transparency optimization, which allows relevant feasibility studies behind managerial decisions.

9) Our design was successfully and representatively tested and adopted. The potential for its application extension includes, among other things, the information safety area.

10) There are grounds to highlight a related area of research in economics, informatics and conflictology - economic information conflictology, which incorporates as a component of information security in relation to the economy.

\section{References:}

Antopol'sky, A.B. 2016. Infosphere of Defense Industrial Complex: A Monograph. Moscow, Russia: MAKS-Press Publishing House.

Barynkin, V.M. 2000. Military Conflict Studies: A Monograph. Moscow, Russia: Russian Aeronautical Society Publishing House.

Bodrunov, S.D., Dmitriev, O.N. \& Koval'kov, Yu.A. 2002. Aviation Industry of Russia at Beginning on eve of $21^{\text {st }}$ Century: Efficient Management Problems: Part $1^{\text {st }}$ and Part $2^{\text {nd }}$. A Monograph. Saint-Petersburg, Russia: Aerospace Equipment Corporation Publishing House.

Bodrunov, S.D., Dmitriev, O.N. \& Koval'kov, Yu.A. 2003. Structural Assessment of Consequences of Managerial Decisions for Enterprises. Moscow, Russia: Gnom and D Publishing House.

Bundin, M.V. 2017. Personal Data within Confidential Information System. Ph.D., diss. Moscow, Russia: The Institute for Legislation and Comparative Law under the Government of the Russian Federation.

Bwalya, K.J. \& Zulu, S.F.C. 2012. Handbook of Research on E-Government in Emerging Economies: Adoption, E-Participation, and Legal Frameworks, 2 Volumes.

Dmitriev, O.N. \& Novikov, S.V. 2017. Conception of Managing of Fuzzy Institutional Meso-Level Organizational Separations in Context of Product Projects Internationalization. European Research Studies Journal, XX, 4B, pp. 3-30.

Dmitriev, O.N. 2002. Intellectual Information Technology for Feasibility Studies of Marketing Decisions. A Monographic image of the thesis for the degree of doctor of economic Sciences. Moscow, Russia: Gnom and D Publishing House.

Dmitriev, O.N. 2005. System Analysis in Management. The $5^{\text {th }}$ Edition. Moscow, Russia: Good Word Publishing House.

Dmitriev, O.N. 2017. Strategic Problems and Directions of Progression Rehabilitation of Management Systems of High Technology Complex of Russia. Microeconomics, I6, 5-24.

Dmitriev, O.N. \& Novikov, S.V. 2018. Transformation of Russian Tax System as Part of Integration of Economy into International High technology Production Field of Socio-economic Systems. European Research Studies Journal, XXI, 4, 400413.

Germeyer, Yu.B. 1976. Non-Antagonistic Games. Moscow, USSR: Science Publishing House. 
Glushkov, V.M. 1974. An Introduction to Automated Control Systems. The $2^{\text {nd }}$ Edition, Amended and Added. Kiev, Russia: Tekhnika Publishing House.

Goryainov, V.B., Pavlov, I.V., Tsvetkova, G.M. 2001.

Mathematical Statistics. Moscow: Bauman Moscow Technical State University Publishing House.

Gunin, D.I. 2008. Information Transparency and Confidentiality: Theoretical and Legal Aspect. Ph.D., diss. Yekaterinburg, Russia. Ural State Academy of Law.

Kanashchenkov, A.I., Dmitriev, O.N., Yekshembiyev, S.Kh. \& Minaev, E.S. 2013. Strategic Corporate Management: Fundamental and Applied Problems. The $2^{\text {nd }}$ Edition, Corrected and Amended. Moscow, Russia: Moscow Aviation Institute Publishing House and Good Word Publishing Houses.

Kanashchenkov, A.I., Dmitriev, O.N., Ekshembiev, S.Kh. 2004. Organization of Self-Management of Financial and Economic Potential of a Corporate Structure: A Monograph. Moscow, Russia: MAI and Good Word Publishing Houses.

Khubiev, R.K. 2009. Transparency as Competitiveness Driver. Ph.D., diss. Lomonosov Moscow State University.

Leokhin, Y.L. 2009. Scientific Fundamentals of Control of Parameters of Corporate Networks Structures. Ph.D., diss. Moscow State Institute of Electronics and Mathematics.

Naydenova, Yu.N. 2017. The Influence of R\&D Information Disclosure Strategy on Prices of Shares of a Public Company. PhD diss. abstract. Moscow: Higher School of Economics.

Rosin, M.F. 1970. Statistical Dynamics and Management System Efficiency Theory. Moscow: Machine Building Publishing House.

Shannon, C. 2002. Works in Information Theory and Cybernetics. Moscow, Russia: Foreign Literature Publishing House.

Shpak, Yu.A. 2007. Designing Databases. Moscow, Russia: EKSMO Publishing House.

Teslya, Yu.A. 2009. Transparency as Competitiveness Growth Driver for Russian Companies Seeking International Funding. Ph.D., diss. Saint-Peterborough State University of Economics and Finance.

Wiener, N. 1968. Cybernetics, or Control and Communication in Animal and the Machine. The $2^{\text {nd }}$ Edition. Moscow, USSR: Soviet Radio Publishing House.

Willink, R. 2013. Measurement Uncertainty and Probability. Cambridge: Cambridge University Press.

Yegorov, M.M. 2006. Municipal Incubator Management of Regional Small Industrial Businesses: A Monograph. Moscow, Russia: Good Word and MAI Publishing House.

Zhu, K. 2005. Information Transparency Hypothesis: Economic Implications of Information Transparency in Electronic Markets // Advances in the Economics of Information Systems // Idea Group Publishing. 